\title{
Identifikasi Pemanfaatan Danau Ranu Grati oleh Stakeholders dengan Participatory Mapping
}

\author{
Elok Wuri Safitri dan Hertiari Idajati \\ Departemen Perencanaan Wilayah dan Kota, Fakultas Teknik Sipil dan Perencanaan, Institut \\ Teknologi Sepuluh Nopember \\ e-mail: hertiari.idajati@urplan.its.ac.id
}

\begin{abstract}
Abstrak-Danau Ranu Grati merupakan salah satu danau alami di Provinsi Jawa Timur yang berada di Kecamatan Grati, Kabupaten Pasuruan. Danau Ranu Grati selain menjadi destinasi wisata wilayah sekitarnya juga digunakan berbagai kegiatan sosial, ekonomi, dan budaya masyarakat lokal. Adanya konflik pemanfaatan perairan Danau Ranu Grati yang mengakibatkan kerugian pada kedua kegiatan utama. Upaya yang dapat dilakukan untuk meminimalisir konflik yaitu melalui pengendalian kegiatan pemanfaatan melalui arahan pemanfaatan dan alokasi lahan. Guna mencapai hal tersebut diperlukan identifikasi kegiatan pemanfaatan eksisting melalui participatory mapping yang dilakukan kepada enam responden. Hasil participatory mapping menunjukkan bahwa terdapat kegiatan pemanfaatan meliputi penebaran benih, pembersihan gulma, pemberian probiotik, wisata dan rekreasi air, upacara adat Distrikan, latihan rutin komunitas dayung, budidaya KJA dan keramba tancap, pertanian lahan endapan, sebaran perangkap ikan, pemancingan serta kegiatan ekplorasi kawasan wisata oleh pengunjung. Luas total pemanfaatan mencapai 83,49 hektar atau $42,8 \%$ luas perairan danau.
\end{abstract}

Kata Kunci-danau, keramba, participatory mapping, stakeholders, wisata.

\section{PENDAHULUAN}

$\mathrm{P}$ OTENSI danau dan situ di Indonesia tercatat sebanyak 1.594 yang tersebar di masing-masing provinsi. Besarnya potensi sumber daya air Indonesia mendorong pemanfaatan danau untuk memenuhi kebutuhan air bersih, pengairan lahan pertanian, wisata pemandangan, pertambangan dan wadah budidaya ikan air tawar. Jawa Timur sebagai provinsi dengan 12 danau dan situ atau hanya sebesar $0,75 \%$ dari total keseluruhan di Indonesia. Meskipun tidak banyak, danau dan situ di Jawa Timur terkenal akan keindahan alamnya. Salah satu danau alami di Jawa Timur yaitu Danau Ranu Grati yang terletak di Kecamatan Grati, bagian Timur Kabupaten Pasuruan.

Danau Ranu Grati selain menjadi destinasi wisata wilayah sekitarnya, juga digunakan dalam berbagai kegiatan sosial, ekonomi, dan budaya masyarakat lokal. Saat ini perairan Danau Ranu Grati mengalami penurunan kualitas yang disebabkan dari meningkatnya pencemaran pakan dan kotoran ikan pada budidaya keramba. Dapat dipastikan kondisi tersebut menyebabkan kerugian budidaya keramba itu sendiri dan penataan keramba yang tidak teratur mengurangi estetika Danau Ranu Grati sebagai destinasi wisata. Berkurangnya daya tarik wisata mengakibatkan pendapatan dari sektor wisata menurun. Sehingga terjadi konflik pemanfaatan sumber daya antara kedua kegiatan tersebut meskipun secara fisik tidak dapat dilihat dengan jelas. Konflik pemanfaatan yang terus berlanjut akan mendatangkan kerugian ekologis dan ekonomi hingga menghambat potensi sosial budaya yang seharusnya dapat dikembangkan di sekitar kawasan Danau Ranu Grati. Hal ini juga disebabkan kurangnya koordinasi antar-stakeholder yang melakukan kegiatan pemanfaatan di kawasan danau.

Dalam upaya mencapai tujuan pengembangan Danau Ranu Grati sebagai destinasi wisata alam, maka perlu dilakukan upaya penyelesaian konflik dengan cara mengendalikan kegiatan pemanfaatan melalui arahan dan alokasi lahan di kawasan Danau Ranu Grati. Pengendalian kegiatan pemanfaatan didahului dengan mengidentifikasi kegiatan pemanfaatan eksisting pada wilayah perairan Danau Ranu Grati. Kegiatan tersebut berupa alokasi wilayah perairan oleh pihak-pihak yang menggunakan Danau Ranu Grati untuk keperluannya masing-masing. Pihak-pihak tersebut selanjutnya dipilih berdasarkan hasil analisis stakeholders. Dengan participatory mapping, maka dapat diketahui berbagai kepentingan stakeholders agar selanjutnya dapat menentukan tindakan jangka panjang untuk mengatasi penurunan kualitas perairan dan kerusakan lingkungan di kawasan Danau Ranu Grati.

\section{METODOLOGI PENELITIAN}

\section{A. Populasi dan Sampel}

Populasi dalam penelitian ini adalah narasumber dari para pihak yang memiliki pengaruh dan berkepentingan terhadap kegiatan pemanfaatan Danau Ranu Grati Kabupatn Pasuruan. Pengambilan sampel dalam penelitian ini menggunakan teknik purposive sampling, yaitu teknik pengambilan sampel yang didasarkan pada tujuan penelitian yang spesifik terhadap narasumber yang dituju sebagai stakeholder penelitian.

Pengambilan sampel menggunakan teknik Purposive Sampling pada sasaran dua yang digunakan untuk mengidentifikasi kegiatan pemanfaatan eksisiting di wilayah studi berdasarkan keterangan yang dapat digali dari masingmasing sampel. Purposive sampling fokus pada pemilihan sampel yang berupa responden kunci yang mampu menjelaskan kebutuhan data sesuai variabel dalam sasaran dua. Sebelum melakukan sampling perlu dilakukan analisis stakeholder guna mengetahui kepentingan dan pengaruh pihak-pihak terkait dalam penelitian ini. 


\section{B. Stakeholder Analysis}

Analisis stakeholders diawali dengan mengidentifikasi stakeholders yang memiliki kepentingan dan pengaruh dalam pemetaan stakeholders pada lampiran 1 dan tabel 1 berikut ini. Kemudian diperoleh stakeholders kunci dalam penelitian ini terdiri dari tiga kelompok utama yang terlihat pada tabel 2, yang kemudian disebut sebagai responden peneltian.

Tabel 1.

Pemetaan Stakeholders Menurut Tingkat Kepentingan dan Tingkat Pengaruh Tingkat $\quad$ Pengaruh Aktivitas Stakeholders

\begin{tabular}{ccccccc}
$\begin{array}{c}\text { Kepentingan } \\
\text { Stakeholders }\end{array}$ & $\mathbf{0}$ & $\mathbf{1}$ & $\mathbf{2}$ & $\mathbf{3}$ & $\mathbf{4}$ & $\mathbf{5}$ \\
\hline 0 & & & & & \\
1 & & $\mathrm{P} 3$ & $\mathrm{P} 4$ & & & \\
2 & & $\mathrm{~S} 1$ & & & \\
3 & & & $\mathrm{O} 1$ & & \\
4 & & & & $\bullet \mathrm{P} 1$ \\
& & & & - 2 \\
5 & & & B 1 \\
& & & B 2 \\
\hline \hline
\end{tabular}

: Stakeholders Kunci

Tabel 2.

Kelompok Stakeholders Penelitian

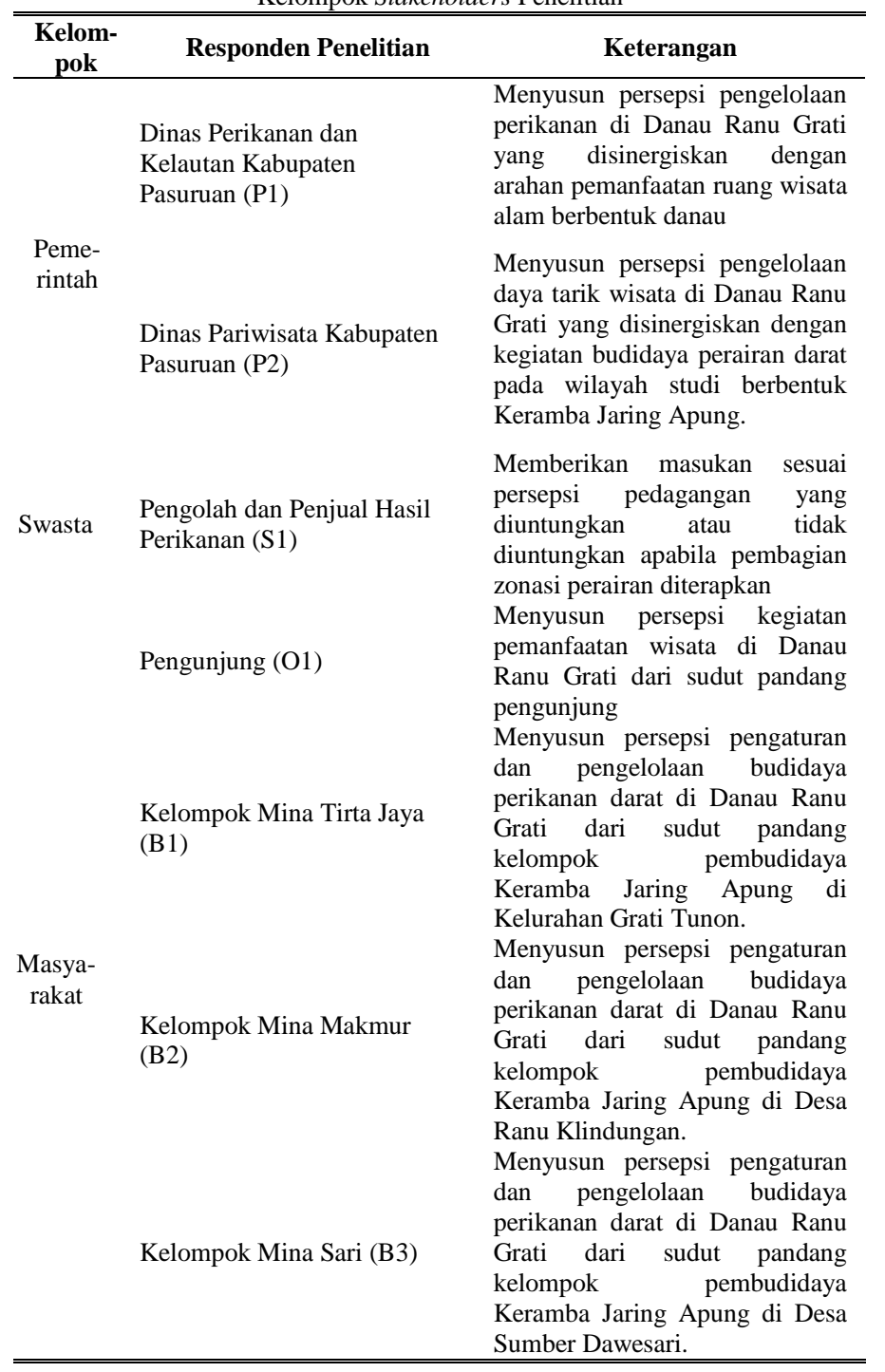

\section{Participatory Mapping}

Teknik participatory mapping atau pemetaan partisipatoris merupakan mekanisme penggalian informasi berbasis keruangan atau spasial terhadap suatu objek amatan yang sumber informasinya adalah masyarakat atau pihak berkepentingan lain. Teknik ini mengandalkan kompetensi mendalam yang dimiliki oleh responden untuk menjelaskan jenis dan bentuk kegiatan serta di mana lokasinya dan besar pengaruhnya terhadap kondisi di sekitarnya. Bermacammacam media yang dapat dipakai untuk melakukan participatory mapping. Dalam penelitian perumusan prinsip zonasi perairan kawasan Danau Ranu Grati menggunakan media peta dasar wilayah penelitian yang berupa kertas berukuran A4 seperti yang terlihat pada gambar 1. Media ini selanjutnya dilengkapi daftar pertanyaan atau kuisoner dan dibawa kepada masing-masing responden penelitian.

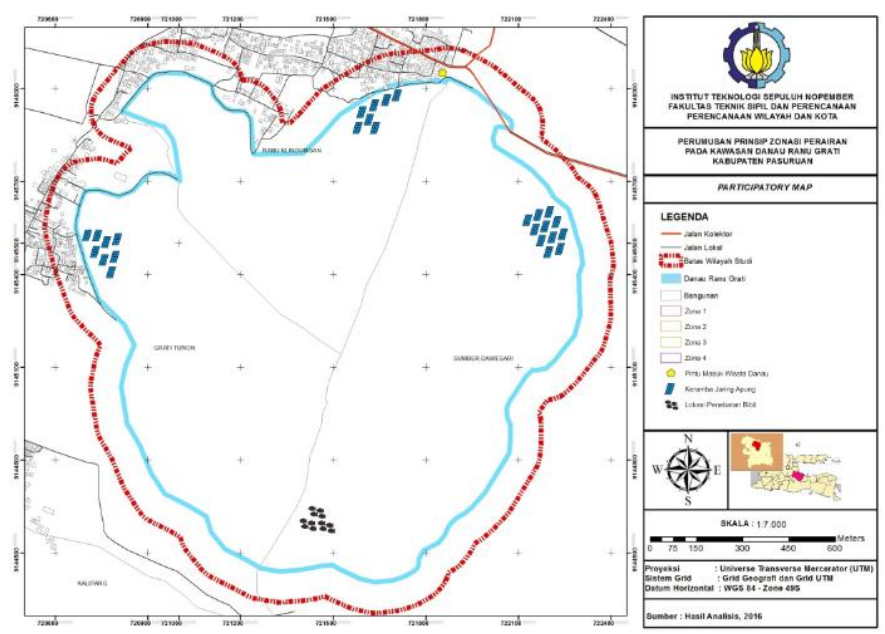

Gambar 1. Media Participatory Mapping Berupa Peta Garis Kawasan Danau Ranu Grati.

\section{HASIL DAN PEMBAHASAN}

Berdasarkan mekanisme participatory mapping maka diperoleh hasil pemetaan partisipatoris oleh responden penelitian sebagai berikut.

\section{- Hasil Participatory Mapping Responden P1}

Narasumber sebagai Responden P1 memaparkan kegiatan pemanfaatan eksisting yang ada di wilayah penelitian meliputi kegiatan penebaran benih ikan, pembersihan gulma dan pemberian probiotik di wilayah Kelurahan Grati Tunon dan Desa Sumber Dawesari. Adapun total luasan pemanfaatan wilayah perairan yang dilakukan Responden P1 memiliki luas total 3,42 hektar. Kegiatan Responden P1 ditunjukkan pada gambar 2 dan digambarkan dengan crosshatch pattern berwarna biru tua pada gambar 8 . 


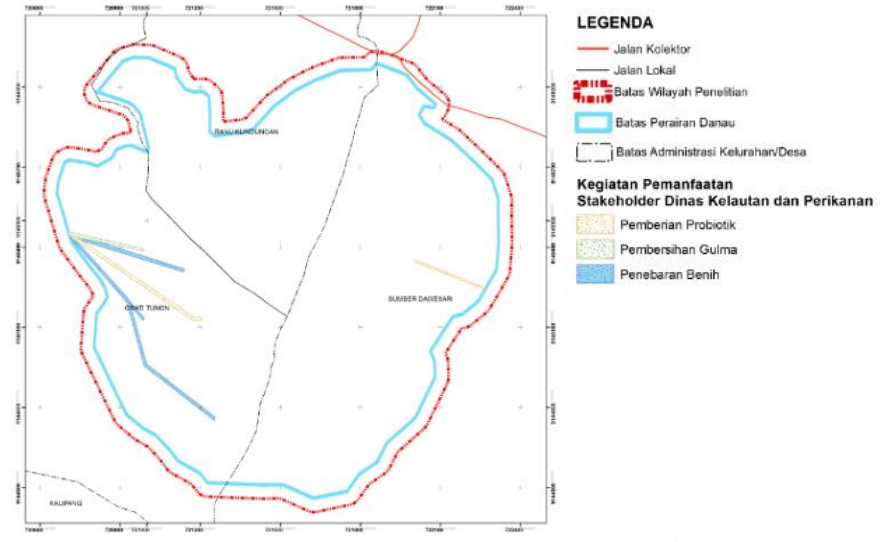

Gambar 2. Hasil Participatory Mapping Kegiatan Pemanfaatan Danau Ranu Grati oleh Dinas Kelautan dan Perikanan.

- Hasil Participatory Mapping Responden P2

Narasumber sebagai Responden P2 memaparkan kegiatan pemanfaatan eksisting yang ada di wilayah penelitian meliputi kegiatan wisata rekreasi air, upacara adat Distrikan atau Larungan, olahraga air komunitas dayung Baru Klinting dan wisata keliling danau yang berjarak 100 meter dari tepi danau. Diperoleh total luasan pemanfaatan wilayah perairan yang dilakukan Responden P2 memiliki luas 16,5 hektar. Kegiatan Responden P2 ditunjukkan pada gambar 3 dan digambarkan dengan stripped pattern berwarna biru tua pada gambar 8 .

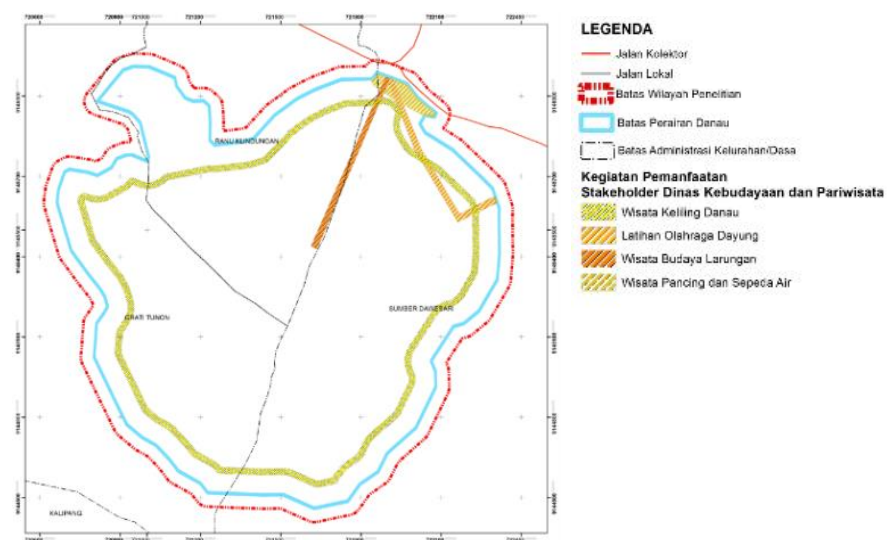

Gambar 3. Hasil Participatory Mapping Kegiatan Pemanfaatan Danau Ranu Grati oleh Dinas Kebudayaan dan Pariwisata.

\section{- Hasil Participatory Mapping Responden B1}

Narasumber sebagai Responden B1 memaparkan kegiatan pemanfaatan eksisting yang ada di wilayah penelitian meliputi kegiatan budidaya perikanan keramba jaring apung, pertanian padi di lahan endapan dan adanya sebaran jaring perangkap ikan yang merata di perairan danau. Luasan pemanfaatan wilayah perairan yang dilakukan Responden B1 memiliki luas total 23,97 hektar. Kegiatan Responden B1 ditunjukkan pada gambar 4 dan digambarkan dengan stripped pattern berwarna ungu tua dan titik-titik sebaran jaring perangkap ikan pada gambar 8 .

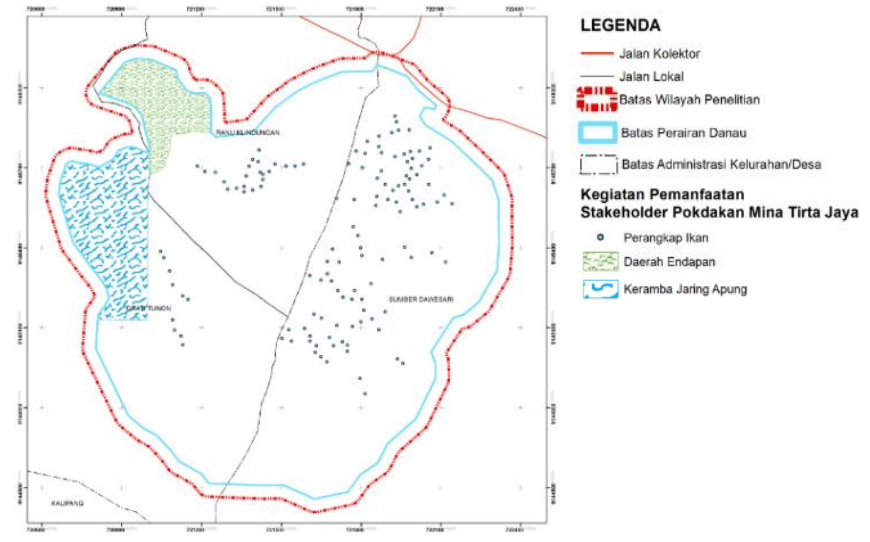

Gambar 4. Hasil Participatory Mapping Kegiatan Pemanfaatan Danau Ranu Grati oleh Pokdakan Mina Tirta Jaya.

\section{- Hasil Participatory Mapping Responden B2}

Narasumber sebagai Responden B2 memaparkan kegiatan pemanfaatan eksisting yang ada di wilayah penelitian meliputi kegiatan budidaya perikanan keramba jaring apung (KJA) dan keramba tancap. Luasan wilayah peruntukkan keramba tersebut sebesar 11,57 hektar. Kegiatan Responden B2 ditunjukkan pada gambar 5 dan digambarkan dengan stripped pattern berwarna violet pada gambar 8 .

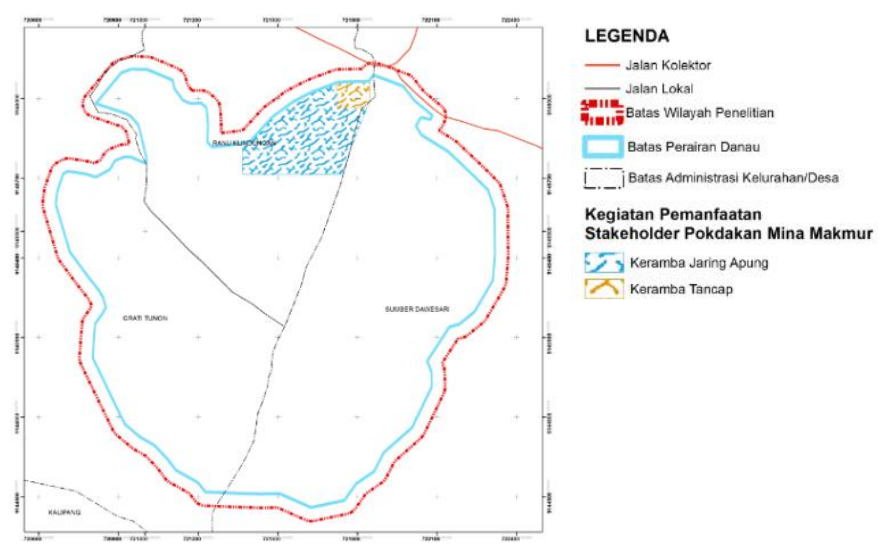

Gambar 5. Hasil Participatory Mapping Kegiatan Pemanfaatan Danau Ranu Grati oleh Pokdakan Mina Makmur.

\section{- Hasil Participatory Mapping Responden B3}

Narasumber sebagai Responden B3 memaparkan kegiatan pemanfaatan eksisting yang ada di wilayah penelitian meliputi kegiatan budidaya perikanan keramba jaring apung dan lokasi pemancingan komersial. Luasan peruntukkan keramba sebesar 27,63 hektar. Kegiatan Responden B3 ditunjukkan pada gambar 6 dan digambarkan stripped pattern berwarna ungu muda pada pada gambar 8 . 


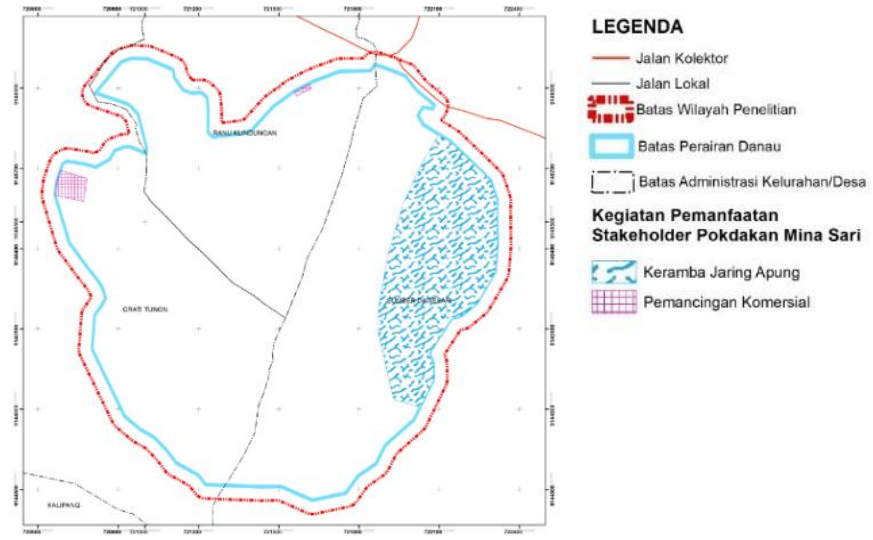

Gambar 6. Hasil Participatory Mapping Kegiatan Pemanfaatan Danau Ranu Grati oleh Pokdakan Mina Sari.

\section{- Hasil Participatory Mapping Responden O1}

Narasumber sebagai Responden O1 memaparkan kegiatan pemanfaatan eksisting yang dilakukan hanya berada pada kawasan wisata. Kegiatan Responden juga terbatas pada area kawasan yang dapat dieksplorasi dengan berjalan kaki. Adapun luas kawasan wisata sebesar 0,4 hektar. Kegiatan Responden O1 ditunjukkan pada gambar 7 atau dengan crosshatch pattern berwarna hijau pada pada gambar 8 .

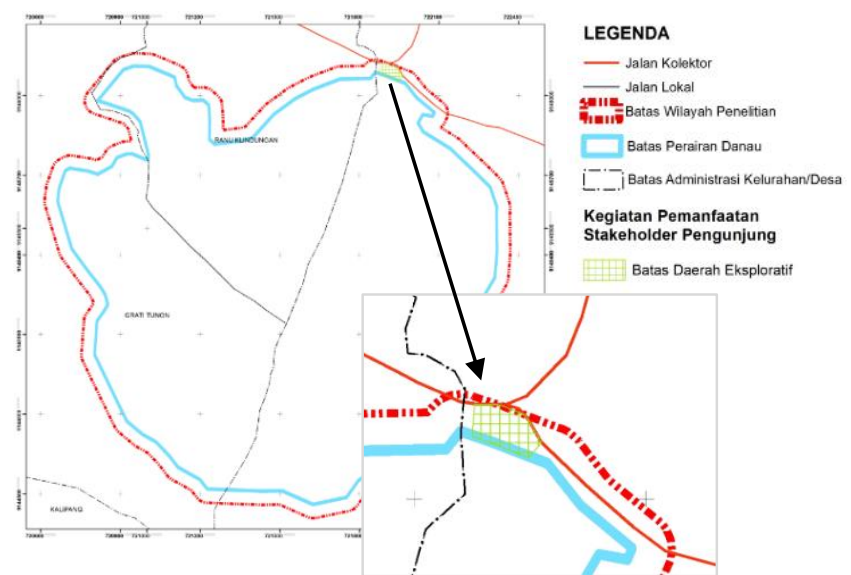

Gambar 7. Hasil Participatory Mapping Kegiatan Pemanfaatan Danau Ranu Grati oleh Pengunjung Wisata.

\section{- Hasil Participatory Mapping Kegiatan Pemanfaatan oleh Seluruh Responden}

Berdasarkan hasil participatory mapping masing-masing responden maka diperoleh gambar 8. Luas pemanfaatan perairan kurang lebih mencapai 83,49 hektar atau sebesar $42,81 \%$ dari wilayah perairan danau. Pada gambar tersebut dapat terlihat bahwa beberapa kegiatan saling tumpang tindih (overlapping). Sebagian yang dapat menimbulkan konflik yaitu pada kegiatan wisata keliling danau yang lintasannya berada pada wilayah KJA di tiga kelurahan/desa.

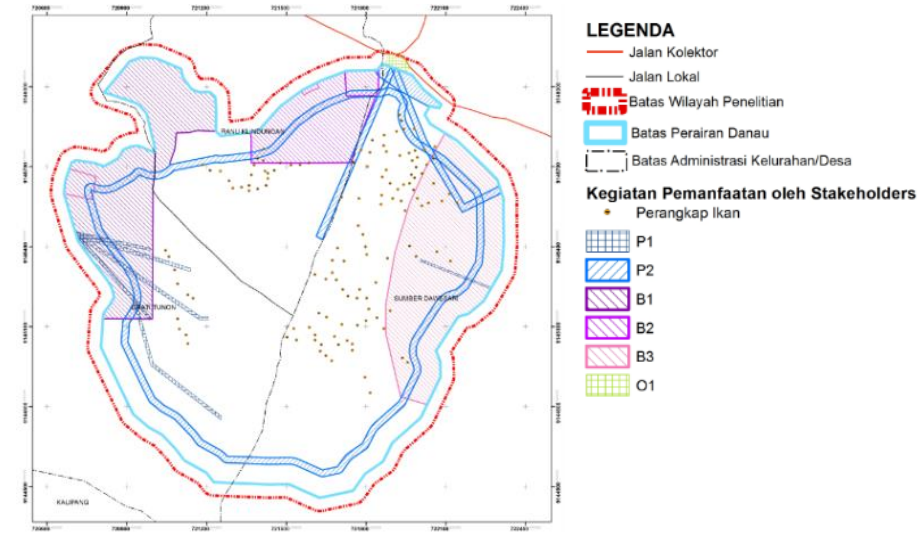

Gambar 8. Hasil Participatory Mapping Kegiatan Pemanfaatan Danau Ranu Grati oleh Stakeholders.

\section{KESIMPULAN}

Berdasarkan hasil dan pembahasan maka identifikasi kegiatan pemanfaatan eksisting Danau Ranu Grati melalui prticipatory mapping responden penelitian, dapat ditarik kesimpulan bahwa:

1. Stakeholders Analysis menghasilkan sejumlah 6 (enam) stakholder kunci sebagai responden penelitian yang memiliki pengaruh dan kepentingan dalam mempengaruhi kegiatan pemanfaatan Danau Ranu Grati, diantaranya:

- Dinas Kelautan dan Perikanan Kabupaten Pasuruan, dengan kode P1

- Dinas Kebudayaan dan Pariwisata, dengan kode P2

- Pokdakan Mina Tirta Jaya, dengan kode B1

- Pokdakan Mina Makmur, dengan kode B2

- Pokdakan Mina Sari, dengan kode B3

- Pengunjung Wisata, dengan kode O1

2. Pemanfaatan eksisting oleh Responden P1 meliputi kegiatan penebaran benih, pembersihan gulma dan pemberian probiotik seluas 3,42 hektar.

3. Pemanfaatan eksisting oleh Responden P2 meliputi kegiatan wisata rekreasi air, upacara adat Distrikan atau Larungan, latihan rutin olahraga air komunitas dayung Baru Klinting dan wisata keliling danau seluas 16,5 hektar.

4. Pemanfaatan eksisting oleh Responden B1 meliputi kegiatan budidaya KJA, pertanian lahan endapan dan sebaran perangkap ikan seluas 23,97 hektar.

5. Pemanfaatan eksisting oleh Responden B2 meliputi kegiatan budidaya KJA dan keramba tancap serta lokasi pemancingan seluas 11,57 hektar.

6. Pemanfaatan eksisting oleh Responden B3 meliputi kegiatan budidaya KJA dan pemancingan seluas 27,63 hektar.

7. Pemanfaatan eksisting oleh Responden $\mathrm{O} 1$ meliputi kegiatan eksplorasi kawasan wisata seluas 0,4 hektar.

8. Total keseluruhan pemanfaatan eksisting seluas 83,49 hektar atau sebesar $42,81 \%$ dari luas perairan Danau Ranu Grati.

9. Hasil participatory mapping seluruh responden menghasilkan daerah-daerah overlapping yang dapat menimbulkan konflik pemanfaatan. Selanjutnya hasil tersebut dapat dijadikan pertimbangan arahan 
pengendalian kegiatan pemanfaatan Danau Ranu Grati agar tidak mendatangkan baik kerugian ekonomi maupun ekologis yang dapat menghambat potensi sosial budaya sebagai destinasi wisata, yang seharusnya dapat dikembangkan di sekitar kawasan.

\section{DAFTAR PUSTAKA}

[1] Undang-Undang No. 31 Tahun 2004 Tentang Perikanan.

[2] Undang-Undang No. 26 Tahun 2007 Tentang Penataan Ruang.

[3] Undang-Undang Republik Indonesia No. 32 Tahun 2009 Tentang Perlindungan dan Pengelolaan Lingkungan Hidup.

[4] Peraturan Menteri Negara Lingkungan Hidup No. 28 Tahun 2009 Daya Tampung Beban Pencemaran Air Danau dan/atau Waduk.
[5] Peraturan Daerah Provinsi Jawa Timur No. 5 Tahun 2012 Tentang RTRW Provinsi Jawa Timur Tahun 2011-2031.

[6] Dahuri, Rokhmin, Jacub Rais, Sapta P. Ginting, dan M.J. Sitepu, Pengelolaan Sumber Daya Wilayah Pesisir dan Lautan Terpadu. Jakarta: Pradnya Paramita (2001).

[7] Kristanto, Philip, Ekologi Industri. Yogyakarta: Andi Offset (2002).

[8] Pontoh, Otniel, “Analisis Usaha Budidaya Ikan Dalam Jaring Apung di Desa Tandengan Kecamatan Eris Kabupaten Minahasa, Sulawesi Utara," Pasific Journal Vol.2, No. 7 (2012) 1424-1428.

[9] Sastrayuda, Gumelar S. (2010). Konsep Pengembangan Wisata Danau. Hand Out Mata Kuliah Concept Resort and Leisure. Available: http://file.upi.edu/Direktori/FPIPS/LAINNYA/GUMELAR_S/.

[10] Yuliastuti, E., "Kajian Kualitas Air Sungai Ngringo Karanganyar dalam Upaya Pengendalian Pencemaran Air," Thesis, Program Pascasarjana, Universitas Diponegoro, Semarang (2011). 